\title{
Competitive Dysfunctions: The Contribution for Services of Ophthalmology Clinics
}

\author{
Edson Yoshito Yamamoto \\ Ophthalmology Department, Universidade Federal de São Paulo \\ Rua Izar, 50, apto. 33, São Paulo 04127-070, Brazil \\ Tel: +55-11-5575-5379Ｅ-mail: yamamoto.edson@gmail.com.br \\ Marinho Jorge Scarpi \\ Ophthalmology Department, Universidade Federal de São Paulo \\ Rua Botucatu, 824, São Paulo 03138-010, Brazil \\ Tel: +55-11-5575-5379Ｅ-mail: scarpi@terra.com.br \\ Mauro Maia Laruccia (Corresponding author) \\ School of Management, Pontifícia Universidade Católica de São Paulo \\ Rua Ministro de Godoi, 969, São Paulo 03138-010, Brazil \\ Tel: +55-11-8286-7467Ｅ-mail: mauro.laruccia@gmail.com
}

Received: September 6, 2011

Accepted: September 26, 2011 Published: December 15, 2011

doi:10.5430/jms.v2n4p64

URL: http://dx.doi.org/10.5430/jms.v2n4p64

\begin{abstract}
Research addresses the competitiveness of medical services and evaluates the size of gaps concerning dysfunctions strategic, competitive and operational. Investigate strategic dysfunction and the impact of operational dysfunction in ophthalmology clinics. The sample consists of subjects related to clinics located in Sao Paulo, Brazil. The results showed that the average gap value is 0.61 , which is significantly higher (at the significance level of 0.05 ) than the average 0.43 of functions. We concluded that the strategic alignment (no gaps) rests in the hands of the physician owner who has some closeness with the preferences of their clients. For this physician owner should focus on the relationship with the manager of the clinic, in order to check if the value delivered to clients is the value that they want.
\end{abstract}

Keywords: Strategic Dysfunctions, Competitive Dysfunctions, Strategy, Services, Medical Services

\section{Introduction}

Companies seek competitive advantages needs to know where you are and where to go (Kaplan et al 2000). Ansoff (2007), Porter (1980, 1985), Hammel and Prahalad (1997), Grönroos (1990) and Chandler (1999) consider competition as a phenomenon directly related to the characteristics presented by an industry or a product. In this case, competitiveness phenomenon can be associated with the ophthalmology clinics industry. The goal is to ensure the survival the company. The possibility to take into account certain factors of competitiveness, i.e., internal elements that can generate or influence (positively or negatively) competitive advantage (Meireles, 2000). Competitive advantage there are the aspect of the product or services that customers recognize in a company as a differentiator over other companies and, therefore, attracted to the company's services. Emphasizing that it is essential that feature add value to the customer competitive advantage. Adding value is always desirable, but not required. The strategy some aspects considered as of paramount importance the condition of acceptance by customers. Overall, internal aspects of the company that does not reflect the relation with customers do not create a competitive advantage (Zaccarelli \& Enoki, 2002).

If competitive advantage is only obtained with the internal aspects that arise in the relationship with customers, the methodology of Zeithaml et al. (1990) is appropriate to evaluate the appropriateness of certain aspects of internal 
customers' expectations. The methodology of these authors, considered here, as a theoretical framework is appropriate to verify the existence of gaps and thus determine the potential competitive company.

The gap between the competitive factors valued by customers and the performance goals prioritized by the strategy of providing the service is the dysfunction strategic, the gap between the performance goals prioritized by the strategy of providing the service and weapons capabilities of the competition in achieving these goals called operational dysfunction. The existence of these two gaps generates a third, related to the potential of weapons of competition to satisfy customers. Competitive dysfunction is the gap between the competitive factors valued by customers and the ability of the competition in full consideration.

\section{Literature}

\subsection{Competitiveness}

Change in the global environment means turbulence. According to Laruccia (2009), market turbulence changes products and processes as well business competitiveness. Turbulence affects externally markets, customer demand, and technology. Competitiveness is the ability of companies to develop and achieve competitive strategies that may allow the addition or maintenance of sustainable market positions, and makes a company more successful than others (Porter, 1980; Lall, 2001; Ferraz et al., 1997; Hamel \& Prahalad, 1993; Esser et al., 1994; and Lanzer et al., 1997).

Ferraz et al. (1997) and Machado-da-Silva \& Fonseca (1999), suggests that competitiveness must be efficient and effective. Companies will be competitive when offers quality of services differentiation or the lower costs are in relation to its competitors (Krugman, 1994). For Quinn \& Hilmer (1994), crucial assistance could be addressed to the intellectual or knowledge management system that maintains the competitiveness.

Boljwin \& Kumpe (1990) discusses competitiveness based on three aspects: productivity, quality and flexibility. It is essential ability to respond to dynamic fluctuations in market demand. To Zaccarelli \& Enoki (2002) the effort in organizations should be focused on the ability to try new technologies, new markets and improved management methods, or the redesign of business processes and the seamless integration of value chains of business, customers and suppliers. Schumpeter (1984), Freeman (1993), Dosi (1988a, 1988b), Nelson \& Winter $(1977,1982)$ the ability to innovate is a way to achieve a sustainable development and create competitive advantage.

Coutinho \& Ferraz (1994) emphasizes that a company's competitiveness based on its expertise in formulating and implementing competitive strategies to achieve a sustainable position in the market permanently. To implement strategies Hammel \& Prahalad (1993) argues that organizations have the need for a strategic vision. Competitiveness analysis means conceptualize conquest, development and maintenance of competitive advantage. Rea \& Kerzner (1997) and (Robbins, 2000) defines competitive advantage as a measure which indicates the position of a company relative to its competitors.

Contador (1995) considers the competitive strategy divided into weapons (factors) and fields (locus of competitiveness) of the competition. Presents 16 different fields of competition, aggregated into five groups: price, quality, speed, service and image. Barbosa (2001) consider other aspects of competitiveness, where organizational competitiveness passing through economic factors in addition, to technical and institutional factors.

Machado-da-Silva \& Fernandes $(1998,1999)$ believes that is necessary follow the nature of the activity of each company to understand strategic action taken. Schumpeter (1984) argues that the approach to corporate strategy combines the economic perspective, from the definition of the strengths and weaknesses of the company connecting skills, competencies and capabilities to create conditions to compete. Proença (1999) discusses that the natural asymmetry among firms explains why successful strategies are not easily imitated and then reversed in its effectiveness.

A strategy can be conceived as the formulation of ways to obtain competitive advantages that enhance the competitiveness of the company among consumers, and market advantages that enhance the company's position against competitors (Meirelles 2000). Kotler \& Singh (1981) classified such strategies into two categories: strategies of attack and defense. The approach of these strategies is similar to a battlefield in which firms choose with care the nature and strength of each action to be released on competitors.

\subsection{Customer Perceived Quality}

In view of Albrecht \& Lawrence (1992) and Zaccarelli \& Enoki (2002), to get a higher approval of the customer or a competitive advantage is necessary to understand what customer value, or what valued by the customer so that we delivery their preferences.

We can classify value according Lima Filho (1999) as extrinsic and intrinsic value. Extrinsic value characterized by interpretation related an event or a something as a useful means to lead a goal or purpose. Intrinsic value in relation to a 
relative preference (comparative, personal, situational), characterizing a customer experience, featuring an evaluation of experience by experience itself, regardless of any other consequences that may result from the experience. Thus, intrinsic value is non-utilitarian and playful.

To Zaccarelli \& Enoki (2002), it is clear that the process of realizing the value of something or event has a cognitive component of perception and an affective component of preference. Precisely for this reason, marketers believe that the emphasis on perceived customer value is about the benefit versus sacrifice (Lima Filho, 1999). In this sense, we believe benefits like better quality, new features, convenience, or other practical aspects, psychological or social desirable, and consider the factors as a sacrifice that somehow mean cost to the consumer, such as time, energy, psychological strain and price.

Quality can also be classified on dimension of product quality and quality of service, according Garvin, 1990. Product quality related on we have 1) Performance - fulfilling the purpose, 2) characteristics - appropriateness and effectiveness in the presentation, 3) Compliance - within quality specifications, 4) reliability - the proper functioning, 5) Durability duration, 6) availability of services: technical support and customer service, and 7) fit and finish, quality appearance. Related on quality of service we have 1) tangible, physical facilities, equipment, aspect of people, 2) reliability, running safely and properly, 3) competence - knowledge and ability to perform the service, and quality printing, 4) service: availability, speed and consideration of the sales team, and 5) empathy, care with personalized and individualized attention.

We can also say that the issue of perceived quality and perceived value price are decisive factors influencing the perception of value and as a result, the customer's purchase intention. The perceived price can be understood as the subjective interpretation of objective product price in view of Chang \& Wildt (1994). In other words, according to the reference price that the customer has the product or category that the product belongs on your perception is more or less, because experience makes a difference in perception.

According to Zaccarelli \& Enoki (2002), perceived value proposed as an intervening construct in the relationship of price information and price with no intention to buy (Dodds et al. 1991, Zeithaml 1990). Deal with the perceived value as a trade-off between "giving" and "receive". The sacrifice to pay the established price represent by "give", and it has a negative impact on the development of perceived value, and the "receiving" represent perceived quality about the product, which has a positive effect on perceived value.

The study by Brucks (2000) concludes that the examination of quality dimension varies in complexity. It is essential to note that the concept of quality can be very broad, depending on the category of product or service is interesting to know which quality dimensions considered in judging the consumer (Zaccarelli \& Enoki 2002). Aaker (2004) defines that quality can be defined as the perception of overall quality or superiority of a product or service compared to others. For Garvin (1990), there are many perspectives on what has to be quality, which may be so strong as superiority or excellence.

The value of perceived quality can be identified for the following opportunities generated, according to Aaker (2004) selling point linked to the purchase decision. If the perception is reliable, this will serve to leverage the marketing activities. Otherwise, they become difficult to reverse. Differentiation/position, a measure of the perceived quality helps in brand positioning. Price: the advantage of a high perception of quality may provide charge a higher price (premium price) than the competition. Relating on the distribution channel the image of the channel affected by the products offered and line extensions. The perceived value can be exploited by entry into other product categories.

The brand image enhancing with location information and the selling price of the product or service. According to Andreassen \& Lindestad (1998) the company's image is a significant factor to enhance the attractiveness of the company and its products and services. We can transform the image from the perspective of corporate brand as a mark of success is nothing more than a successful relationship (McKenna, 1993). Hernandez (2001) found that the effect of the brand in perceived value was greater than the effect of price, and Dodds \& Monroe (1991) found that the brands significantly increased the desire to purchase at a given store.

In the work of LeBlanc \& Ngyuen (1996), the corporate image of companies that providing services influenced by five factors: corporate identity, reputation, tangibility of services, level of service, and direct contact. Thus, factors such as appearance, courtesy, empathy and assistance beyond the competence have a significant effect on the process of service evaluation by the customer.

The corporate image can be understood as an important dimension of quality (LeBlanc \& Ngyuen, 1996). According Andreassen \& Lindestad (1998) corporate image has a potential influence on the perceived quality by the customer. Therefore, image has a key role in attracting and retaining customers and, is a function of the cumulative effects of 
customer satisfaction or dissatisfaction arising from their experiences with the service or product.

The strategic vision of customer service that includes: delivery service, operational strategy, the concept of service and target market segments, enables the company to develop skills, productivity and distinct services (generating a lower relative cost) and provide a superior value to its buyers, which results in greater satisfaction (Heskett et al. 1997).

\subsection{Perceived Quality of Medical Services}

Studies such as those of Parasuraman, Zeithaml \& Berry $(1985,1988)$ develop and present their own methods that can be applied to evaluate the quality of services. Similarly, Normann (1993) considers the development of quality in services takes place in a different way of industrial product and demonstrates this by listing a number of differences between industrial products and services. This characterization of service is essential to understand the challenges inherent to the development of quality services. The characteristics given are: a) generally, the service is intangible; b) generally, ownership is not transferred; service cannot be resold; c) generally, the service cannot be demonstrated effectively, because he did not exist before purchase; d) service cannot be stored; e) production and consumption generally match; f) production, consumption and, often, the sale processed in the same location; g) service cannot be transported (though the "producers" often can); and h) buyer or client is directly involved in production, and in most cases, personal contact required.

Giving an objective dimension of how to approach the effective development of the applied quality of service, Lamprecht (1994) and Levitt (1986) consider that the gap between service and "no service" becomes smaller as more discovered in on the service sector.

Quintella et al. (2001), and other authors such as Albrecht \& Lawrence (1992), Berry (1996), Desatnick \& Detzel (1994), Lamprecht (1994) and Normann (1993), argue that the service sector is different enough of the industry to have a differentiated approach. Zeithaml explains perceived quality as the judgment of the consumer about the superiority or excellence of a global service (Zeithaml, 1988). This conforms to quality as a form of attitude (Parasuraman, Zeithaml \& Berry, 1985; Zeithaml, 1988). Also, the perceived quality as a relationship between perceived performances compared to expectations of a service (Grönroos, 1993, Parasuraman et al. 1985). This reference is not widely accepted in the literature on the subject. Cronin \& Taylor (1992) discuss this aspect referring to the fact that the gap between expectations and performance has a direct relation to the perceived quality, as shown in their research.

Urdan \& Huertas (2003) addresses the problem of doctors in Brazil who are facing the deterioration of public health, the high dependence on private health organizations, patients with increasing levels of demand and increased competition between professionals.

Research on quality of service underscores the perceived quality client-based (Garvin, 1984). Perception is a process of organization, interpretation and derivation of meaning of stimuli through the senses (Monroe \& Krishnan, 1985). Feeling is a process of receiving these sensory impressions. Thus, the perception is subjective. The cognition of a stimulus on customer service (or good) is not a "photo" but a "design", which expresses their unique vision of reality. This makes essential to distinguish between attributes of an offer by the company, and the customers' perceptions about them, because customers may differ significantly in their perceptions, and this is affecting the behavior, not the attributes themselves (Howard, 1977).

Ford et al. (1997) call attention to the fact that it is necessary to planning quality of health care services. Health organizations have much in common with many other service industries but show them three singularities (Garvin, 1990). The lack of clarity on the relation between inputs and outputs, largely due to the time required for results manifest, the patients may have difficulty in evaluating the technical aspects, and main hospitals operate with two distinct lines of authority (the staff and doctors), instead of the pyramid of predominantly single command. Moreover, as in many other industries, health services include different types of customers (Berwick et al. 1990).

The patient often knows remarkably brief details of the technical quality, describe Donabedian (1985), although they will appreciate its importance, especially in situations of open threat to health and wellness. The distinction proposed by Grönroos (1990), argue Urdan \& Huertas (2003), between the technical and functional qualities shown to be beneficial for health services. Technical quality refers to the technical field of health care services while the functional quality reflects your interpersonal domain.

Clark (2001) mentions that many medical schools in the United States are changing their curricula to enhance the humanistic qualities inherent in medical work. A comprehensive study on quality of health care carried out with physicians from Australia, Canada, United States, Britain and New Zealand show a challenge (Blendon et al., 2001). The majority of respondents were in favor of reforms that have more time with their patients, but only $33 \%$ to $40 \%$ of them agreed that patient assessments might help to improve the quality. This shows little inclination to meet these physicians 
the patient's interest, despite the value in being able to devote attention to patients.

\section{Procedures and Methods}

This study evaluates the size of gaps concerning dysfunctions strategic, operational and competitive in a series of ophthalmology clinics, and shows that such disorders are significant, resulting in inadequate service provided in relation to competitive factors considered by the patients. By means of questionnaires to patients, physicians, owners and managers of ophthalmology clinics determined the levels of the gaps between them.

The determination of levels of the gaps can be made according to Parasuraman et al. (1988) through the gap analysis by using a scale called SERVQUAL. The dysfunction competitive is the difference between the current position and one that the company. A trade-off matrix derived from the questionnaire SERVQUAL Zeithaml et al. (1990), used to obtain the order and the degree of preference for competitive factors of the parties involved (patients, managers and medical clinic owner), the gaps intensity calculated observed between the parties, defined by 1-r $\mathbf{r}_{s}$ (The agreement is the value $r_{s}$ Spearman r).

Each respondent gave the order of importance of each feature of the service through a matrix of priority. The service of ophthalmology clinics analyzed under a certain perspective that considers the attributes of tangibles, reliability, attention, security and empathy.

The research universe composed by individuals related to ophthalmology clinics located in Sao Paulo, Brazil chosen randomly from a list of 120 clinics. Three samples constructed a) a random sample of 30 owners of medical clinics; b) a matched sample of 30 service managers (responsible for managing the service offered) of the same clinics; and c) a random sample of 90 patients for each ophthalmology clinic with at list three non-paying or health insurance plan patients.

The data collection structured on arrays trade-off based on the SERVQUAL questionnaire. The data collection took a matrix model trade-off associated with issues specific to each sample. Patients, doctor's owners and managers at the ophthalmology clinics responded to a questionnaire, slightly modified.

The trade-off matrix consists of 5 elements compared each other: (1) reliability - the ability to perform the promised service in a safe and accurate; (2) attention - the desire to help customers and maintain an emergency service; (3) safety knowledge and respect of employees and their ability to inspire confidence; (4) empathy, care and personal attention that the company provides to its customers; and (5) tangibles - appearance of physical facilities, equipment, personnel and communication materials.

\section{Results}

The average of existence of the clinics is about 19 years, and there was a clinic with 64 years of existence. Physician's owners' respondent of this survey, the median age, is about 45 years. The presence of women is one third of respondents, and the mean age obtained is less than the overall average (with 41 years of age).

From 30 physicians respondents, 29 have a master or a doctoral degree and six of them, possess a degree in business administration. The average rating for age of managers is about 45 years.

The average length of the relationship between patients with clinics was 5 years. The customer loyalty is unusually high, considering that $50 \%$ of customers stay connected to the clinic for over 4 years, and $20 \%$ are customers for 10 years.

Patient's respondents have an average age of 42 years, and the patient, 17 years younger and 80 years older. The private patients represent $47 \%$ of respondents and the other patients bound to covenants. The agreements reported by patients, Unimed, Sul America and Bradesco Saúde out with 19 patients from a total of 50 respondents (38.0\%). Eight patients did not report their health insurance and other agreements had three or fewer patients each.

A first analysis, comparing the degree of similarity (given by $r_{s}$ ) and gap (given by 1- $r_{s}$ ), shows that there is no significant difference between such variables. Although owned and operated medical clinics in general know the attributes of service that patients value, takes the ophthalmology clinics one by one, those few attuned to the preferences of their own patients. Only an ophthalmology clinic, among the 30 investigated, showed to be properly aligned with the desires of their patients.

The proportion of ophthalmology clinics with no gap is $3.3 \%$. Significance level of 0.05 can be said that the confidence interval for the ratio is $8.0 \%$ to 17.2 considering the 30 clinics surveyed and the possibility of observing at each clinic from 0 to 3 gaps; the maximum number of gaps that could be observed in the clinics surveyed is 90 . The number of gaps observed in total, 74 corresponding to a proportion $\mathrm{p}=0.82$. The confidence interval, significance level of 0.05 for the proportion of observed gaps are $72.7 \%$ to $89.4 \%$. 
The special interest for the research is to determine the extent to which there is dysfunction of the competitive ophthalmology clinics, the object of research. A first analysis, comparing the degree of similarity and the gap shows that there is no significant difference between these variables.

The physician owner has a perception slightly larger than the manager of the clinic with regard to the priorities that their patient's value. Despite the gaps, medical owners and managers aware of the clinical priorities of patients. Doctors and managers know, in general, that patients prioritize the safety and reliability and give less importance to tangibles. Patients for the same position prefer the attention and empathy.

The theoretical approach considers that the operational impact of dysfunction in severe competitive. A regression analysis shows that the gap between the manager of the clinic and patients are positively impacted by the gap between the physician owner and manager, but approximately $20 \%$ of competitive dysfunction may be explained by operational dysfunction. The analysis also shows that the manager of the clinic is in keeping with the physician owner and the greater understanding between the managers of the clinic patients, the existing gap between the manager and the patient decreases - i.e. the smaller the dysfunction competitive.

The results suggest that the gap between doctors and managers is what most impacts on the average function. Although owned and operated medical clinics in general understand the attributes of service that patients value, takes the ophthalmology clinics one by one, those few attuned to the preferences of their own patients. Only an ophthalmology clinic, among the 30 investigated, showed to be properly aligned with the desires of their patients.

\section{Discussion}

This study evaluates the quality of services provided by medical clinics and ophthalmology measures how much the service provided is inadequate in relation to factors valued by patients. According to Donabedian (1985), we should note that the patient does not have the technical capacity of health services and that this lack of knowledge should be observed when assessing the scientific quality. Unlike the scientific quality, patients only able to determine basic quality or evaluate the quality of what is getting.

For Berwick et al. (1990) the best source of information is the patient himself, though it is necessary to achieve the largest number of sources to determine the development of the quality of health services. It is in the same direction as the general principles of quality management, management philosophy as follows based on customer and takes this as a starting point for the alignment of the entire management (Bitner \& Hubbert 1994).

This change of mentality and actions provide a greater understanding of the importance and impact on medical organizations. In the United States is implementing a national network of independent research on the evaluation of patients on the performance of non-clinical or functional quality of care. Health plans should obtain this information and provide them to customers (Duke, 2000).

In this scenario, the connection between doctor and patient demands a shift in focus from transactional to a real relationship, with greater involvement of patients and bi-directional sharing of information (Johnson \& Ramaprasad, 2000). Despite its limitations, the scale of customer-perceived quality (CPQ) outlined here gives rise to physicians a manner significantly improve his actions in office, covering other aspects beyond the technical-scientific related his patients. If it is necessary the development of the instrument or the scale, its implementation and outcomes and benefits it is noteworthy (Anderson, 1995). However, further efforts needed to throw light on the CPQ in health. After all, services, like goods, high quality occupy a privileged position in the competitive market, is no different with health services.

Gomes (2004) states that the professional health care faces the sick person as someone who needs to be treated, cured, and not as a person who is paying very well for his services, and also the belief that if they do, they will be devaluing the practice of medicine. It is also important to remember that the definition of customer is essential. For a clinical ophthalmology customers may be the patient as well as health insurance, where the patient benefits from treatment and health insurance provides payment of the necessary resources. For each type of client attributes analyzed and valued will undergo changes depending on your needs.

According to Yamamoto (2001), the ratio of doctors per inhabitants considered ideal by the World Health Organization is 1:1000. In Brazil this ratio of doctors per population was 1:656 in 2000, and in some states like Sao Paulo, Rio de Janeiro and the Federal District, the number of physicians per population was 1:480, 1:330 and 1:308 respectively. Whereas the ideal number of World Health Organization of 1:1000, there is double or triple the doctors necessary for the population in these states. Also according to Yamamoto, the number of physicians grows at a rate two times higher than population growth of the country. This growing number of doctors causes a greater supply of medical services resulting in increased competition for customers and market. Scarpi (2004) describes that the provision of medical services 
exceeds the demand for these services as a result of lack of policy controlling the number of professionals in health trained annually and the number of schools focused on their training, creating a market highly competitive. In this environment, customers, both users as well as operators of health plans, now have greater bargaining power with increasing demands for medical clinics.

In this competitive scenario it is important that information is more accurate for increasing the competitiveness of organizations. The organizational competitiveness is a key factor for survival in today's market: The need to achieve greater competitive advantage for organizations by being aware of changes in the external environment and internal performance of the same for better placement on the market. We must understand and keep tools and models to the understanding of competitive structures supported by reliable information.

An understanding from an analysis of the phenomenon of change we live in today, points out that some of the key factors were: the stabilization of the currency, changing technology, intense competition and changing customer demands stimulated by legal codes. In this sequence, we can see that health plans that got most of their results from financial investment, no longer rely on this feature, as was the previous model. Increased investment in technology requires the purchase of equipment, facilities and their costs of learning to use and a proper study for return on investment. In a few years ophthalmology suffered profound changes by technological advancement that impacts all of its procedures. The competitive intensity, we have the balance of power between the amount of supply of medical services and their demand, and how the competitors operate in the market. The legal codes are established in this environment causing changes in relations between the providers of medical services and their beneficiaries.

The organizations merged in the changing environment, can be compared to living beings are born, grow and die (Geus, 1997). According to this author specifications for an organization to increase its life as much as possible are: a) sensitivity to the environment: the ability to learn and adapt, b) coherence and identity: developing a personality of their own community and c) tolerance: ability to forge relationships with other organizations, and d) conservative financial management.

Not only are these requirements. Collins and Porras (1994), argue that the clinics must also be able to change to adapt to environmental changes, stimulating the progress of continuous change, maintaining the mission or the core ideology and set, preserving the core, or is, the core values. If the company has a medical mission, it does not change the core, keeping the medical mission as defined. As for the routine processes or side should be modified taking into account the external demands with due concern to distinguish them properly its core ideology. Thus firms become more competitive. The challenge is to keep the medical mission to the sustainability of business.

The strategic vision is greatly simplified when the clinic has focused on customer expectations. In this case the organization would be able to have a focus on weapons (Meireles, 2000) that is, having a concentration of efforts in the clinical factors or causes in the appropriate field where the clinic is competing. The lack of focus, that is, according to Meireles (2000), the diffusion of factors creates a loss of competitiveness because: (1) the greater the focus on weapons appropriate to the field of competition the company, the greater its increase revenue, (2) non-weapons appropriate to the field of competition the company does not contribute to the increase in revenues, and (3) the focus is more important than the degree of potency of Arms (Meireles, 2001).

Technological innovation is thus an important weapon for competitiveness. Pettigrew and Whipp (1993) argue that competitive performance depends on the characteristics of the company or technology but a collection of skills and models of action, and is strongly influenced by industry standards but also by socio-cultural conditions in which it has organization. You can not dissociate the technological innovation of their culture, because as stated by Jackson (2001), learning can only occur in a culture where feedback is not considered a disgrace and the truth is concealed. This environment is important for customer complaints are not concealed the problems and treatments are effective. According Scarpi (2004), the most frequent complaints of customers in medical clinics, are related to telephone service, waiting time for care by physicians, the relationship with the attendants and nursing staff.

It is of paramount importance, therefore, technological innovation and knowledge. Kanter (1989) argues that large companies, prominent in business, through performance or increased capacity for innovation, come out from backstage to center stage, as ideals to be followed by other corporations and their practices disclosed the environment, becoming a reference in benchmarking. Although, important innovation is not the only factor of competitiveness.

Teece et al. (1997) are proponents of VBR (Resource Based View), and say to build competitive advantages perennial their main sources are the development of organizational capabilities because they are very difficult to imitate and they are not and can not be sold. These resources can be of three types, namely: a) tangible assets - are those visible, such as property, facilities and inventories of materials, among others, b) intangible assets - include trade, cultural, technological 
knowledge, patents and accumulated experiences, and c) organizational capabilities-are made up of specific skills across the organization as well as their parts: they arise from complex combinations assets, people and processes of organizations. A vision-based resource includes skills know-how at low cost (efficiency) as well as skills; know how to choose what to do (effectiveness). In addition to these skills, are also included and abilities to advance the organization's performance, in terms of new products or services, or new production processes, sales, financing, distribution etc. These skills are often key features in determining the competitive advantage of organizations. Similarly Treacy and Wiersema (1995) argue that resources should be focused, with particular emphasis in one of the following disciplines: focus on excellence of service (better service), operational excellence (lower cost) or customer relationship (best total solution).

It is not enough however to have features to achieve competitiveness: there is interest in improving the performance and it is essential that it be measured by establishing measurement that satisfies all parties involved (Crandall, 2002). Thus the information system becomes a crucial component of competitiveness. The information coming from the traditional area accounting/financial was sometimes very inadequate and insufficient to support the best decisions with the prospect of business. To give a solution to this need, Kaplan and Norton (1996, 2005) developed the Balanced Scorecard to enable decision-making appropriate to a more competitive era. The Balanced Scorecard puts strategy and vision in the center of attention and not simply control. As proposed by Kaplan and Norton (2000), the Balanced Scorecard includes indicators covering, in addition to the financial, human resources, product development, processing, delivery orders, inventory, turn over of employees and also to customer service.

The evaluation of the customers is one of the key players in this model of assessment and measurement. Thus, an appropriate system of assessment that allows comparison of the performance of a business or activity to another, locally, nationally or internationally, aimed at building a successful company. Campbell (1997), notes that managers need to constantly monitor the performance of their companies and Schwartz (1997) argues that the Balanced Scorecard is a strategic management tool used to determine performance measures, customer service, employee satisfaction and process productivity by using indicators other than financial and with the power to communicate the intentions in the area of strategy and evaluating them in relation to effective performance.

Reflections of an adequate system of indicators beyond the aspects related to competitiveness, since, according to Low and Siesfeld (1998), the taking of decisions by investors, for the most part, are made based on the credibility of the administration, the perceptions the strategic visions of the company, or the prospects for innovation and skills to attract talent, all these factors are inherently non-financial. Awareness of the direction of the organization to the need for the deployment and use of assessment tools that can link the results to the strategic actions, the environment, the return to shareholders and especially the customer service is key to competitiveness.

For Kaplan and Norton (2000), strategy means the displacement of an organization from its current position to a desirable position and hitherto unknown. This change however, according to Porter (1985), can clearly improve or disrupt their position within an industry through its strategic choice. In this sense, the author, competitive strategy, not only responds to the environment, but also tries to model this environment in favor of the company. Porter (1980) presents a model of strategic analysis which considers the components of the five competitive forces: new entrants, substitute products, suppliers, customers and competition level as well as the components of value chain organization. For this author, such components would determine the strategy.

To obtain competitiveness is the need for a strategy, that strategy is suitable for the clinical environment. But we can not track strategy without some advance has been the competitive dysfunction of the clinic, i.e. the gaps or differences between the current situation of the clinic and one that meets customer expectations. In this sense we are discussing the next item, the issue of competitive dysfunction.

This work demonstrates the thesis that the gaps (malfunctions of any kind and taken together) are higher and differ significantly from the strategic functions (alignments of any kind also taken together). This thesis is at the same time, innovative and relevant. Innovative because they were not found in the literature description of how to measure and evaluate the strategic gaps, it is relevant in that it draws attention to the fact that the gaps in competitiveness can be determined and on whether they can act.

The search results can be immediately applied by ophthalmology clinics, providing a competitive re-direction, even partially, from the standpoint of the removal of gaps, highlighting the expectations of customers. Thus, the research has applicability and usefulness immediate.

The assessment of organizational gaps is relevant to those responsible for medical clinics for the formulation of strategies and their implementation. Knowledge of the gaps is an important element to fit the organization's response to threats and opportunities of the external environment. The competitiveness of medical services, specifically on the 
operation of services of clinics at the research can also be useful to providing subsidies for professionals and students.

It seems possible to conclude that the strategic fit (no gaps) lies primarily in the hands of the physician owner who has a high line with the preferences of their customers. To this the physician owner should focus on the relationship with the manager of the clinic, in order not only to pass your perception, but also to check if the value delivered to patients is the value that they want. Thus, the physician owner should focus on the relationship with the manager of the clinic, in order not only to pass your perception, but also to check if the value delivered to patients is the value that they want.

This study has some limitations, namely: (1) it is an empirical research conducted with doctors owners, managers and patients in clinical ophthalmology clinics, located in the Greater Sao Paulo, surveyed in May to August 2004, therefore, does not refer to this study at any other time, another geographical region or object, (2) respondents were asked to reply to specific questionnaires, assuming that the answers: a) have been given effectively respondents to whom the questionnaires were addressed, and b) express the opinion of respondents. Thus, only this set of responses was taken into account, (3) the data collected were analyzed by statistical techniques described above, be appropriate to the type of ordinal data, so the analysis results do not take into account other possible observations arising from use of other analytical tools.

The research is also limited by the following aspects: (1) it is a non-probability survey, and this fact is not possible to extrapolate the results to other doctors owners, managers of other services, other patients or other ophthalmology clinics; (2) the results refer only to the number of respondents surveyed considering that the responses to the questionnaires expressed, in fact, the thought of the respondents.

\section{Final Considerations}

The evaluation of dysfunction competitive in ophthalmology clinics taken one by one, those few are attuned to the preferences of their own patients. Only an ophthalmology clinic, among the 30 investigated, showed to be completely aligned with the desires of their patients, that is, only 3\% of ophthalmology clinics know that the priorities of patient expectations, have the ability to forward this priority internally to your team by the doctor for the manager and prioritize the provision of services in this hierarchy of priorities to the patient.

Competitive dysfunction is almost equally influenced by strategic and operational dysfunctions in ophthalmology clinics whose services can be valued by patients: (1) The average level of dysfunction in strategic ophthalmology clinics surveyed is 0.643 , higher than the complementary strategic role which is 0.357 , (2) The average level of operational dysfunction is 0.561 , and also greater than the additional operational function that is 0.439 ; (3) The impact of operational dysfunction is slightly larger than the impact of erectile function in strategic competitive.

It is recommended that further studies be applied to other types of medical clinics in order to measure and assess the strategic gaps using the method discussed here because the search results can be applied immediately by the clinics, highlighting the expectations of customers.

\section{References}

Aaker, D. A. (2004). Brand portfolio strategy: creating relevance, differentiation, energy, leverage, and clarity. New York: Free Press.

Anderson, E. A. (1995). Measuring service quality at a university health clinic. International Journal of Health Care Quality Assurance, 8(2), 32-37. http://dx.doi.org/10.1108/09526869510081866.

Andreassen, T. W., \& Lindestad, B. (1998). Customer loyalty and complex services: The impact of corporate image on quality, customer satisfaction and loyalty for customers with varying degrees of service expertise. International Journal of Service Industry Management, 9(1), 7-23. http://dx.doi.org/10.1108/09564239810199923.

Ansoff, H. I. (2007). Strategic management. New York: Palgrave Macmillan. http://dx.doi.org/10.1057/9780230590601

Berwick, D. M., Godfrey, A. B., \& Roessner, J. (1990). Curing Health Care: New Strategies for Quality Improvement. John Wiley \& Sons Inc.

Bitner, M. J., \& Hubbert, A. R. (1994). Encounter satisfaction versus overall satisfaction versus quality. In Rust, R.T., \& Oliver, R.L. (Eds.), Service Quality: New Directions in Theory and Practice (pp. 72-94). California: Sage.

Campbell, A. (1997). Keeping the engine humming. (cover story). Business Quarterly, 61(4), 40-46.

Chandler, A. D. (1999). The visible hand: the managerial revolution in American business. Harvard University Press.

Chang, T.-Z., \& Wildt, A. R. (1994). Price, Product Information, and Purchase Intention: An Empirical Study. Journal of the Academy of Marketing Science, 22(1), 16-27. http://dx.doi.org/10.1177/0092070394221002. 
Collins, J. C., \& Porras, J. I. (1994). Built to Last. Harper-Collins.

Crandall, R. E. (2002). Keys to better performance measurement. IEEE Engineering Management Review, 30(3), 58-58. http://dx.doi.org/10.1109/EMR.2002.1032398.

Donabedian, A. (1985). The methods and findings of quality assessment and monitoring: an illustrated analysis. Explorations in quality assessment and monitoring. Health Administration Press.

Duke, S. (2000). Patients nationwide will rate your nonclinical skills. Medical Economics, 77(22), 17.

Geus, A. (2002). The living company. Harvard Business School Press. Harvard Business School Press.

Gomes, F. G. (2004). Gestão de clínicas médicas. São Paulo: Futura. (In Portuguese).

Grönroos, C. (1990). Service management and marketing: managing the moments of truth in service competition. Issues in organization and management series. Lexington Books.

Hamel, G., \& Prahalad, C. K. (1993). Strategy as stretch and leverage. Harvard business review, (march-april), 75-84.

Jackson, K. E. (2001). Empowerment at the Customer Interface. Call Center Magazine, 14(9), 76.

Johnson, G. L., \& Ramaprasad, A. (2000). Patient-Physician Relationships in the Information Age. Marketing Health Services, 20(1), 20 - 27.

Kanter, R. M. (1989). When giants learn to dance: Mastering the Challenges of Strategy, Management and Careers in the 1990s. New York: Simon \& Schuster.

Kaplan, R. S., \& Norton, D. P. (1996). The balanced scorecard: translating strategy into action. New York: Harvard Business School Press.

Kaplan, R. S., \& Norton, D. P. (2000). Having Trouble with Your Strategy? Then Map It. Harvard Business Review, 78(5), 167 - 176.

Kotler, P.; Singh, R. Marketing Warfare in the 1980s. Journal of Business Strategy, winter, p. 30-41, 1981.

Laruccia, M. M. (2009). A essência do raciocínio estratégico empresarial. São Paulo: Baraúna. (in Portuguese).

LeBlanc, G., \& Nguyen, N. (1996). Cues used by customers evaluating corporate image in service firms: An empirical study in financial institutions. International Journal of Service Industry Management, 7(2), 44-56. http://dx.doi.org/10.1108/09564239610113460.

Levitt, T. (1986). The marketing imagination. New York: Free Press.

Low, J., \& Siesfeld, T. (1998). Measures that matter: Wall Street considers non-financial performance more than you think. Strategy and Leadership, 26, 3-4.

Meireles, M. (2000). Armas e campos da competição: uma contribuição a gestão da vantagem competitiva. (Dissertação (Mestrado em Administração)). Universidade Paulista, São Paulo. (in Portuguese).

Meireles, M. (2001). Ferramentas administrativas para identificar, observar e analisar problemas: organizações com foco no cliente. São Paulo: Arte \& Ciência. (In Portuguese).

Parasuraman, A., Zeithaml, V. A., \& Berry, L. L. (1988). SERVQUAL: A Multiple-Item Scale for Measuring Consumer Perceptions of Service Quality. Journal of Retailing, 64(1), 12 - 40.

Pettigrew, A., \& Whipp, R. (1993). Managing change for competitive success. ESRC Competitiveness. Cambridge: Blackwell Business.

Porter, M. E. (1980). Competitive strategy: techniques for analyzing industries and competitors : with a new introduction. New York: Free Press.

Porter, M. E. (1985). Competitive advantage: creating and sustaining superior performance. New York: Free Press.

Scarpi, M. J. (2004). Gestão de Clínicas Médicas. Futura. (In Portuguese).

Schwartz, S. (1997). Transcending financial measures. Insurance \& Technology, 22(4), 52.

Teece, D., Pisano, G., \& Shuen, A. (1997). Dynamic Capabilities and Strategic Management. Strategic Management Journal, 18(7), 509-533. http://dx.doi.org/10.1002/(SICI)1097-0266(199708)18:7<509::AID-SMJ882>3.0.CO;2-Z

Treacy, M., \& Wiersema, F. (1997). The discipline of market leaders: choose your customers, narrow your focus, dominate your market. Perseus Books.

Yamamoto, E. (2001). Os novos médicos administradores: cuidando da saúde dos pacientes e das empresas. Futura. 
Zaccareli, S. B., \& Enoki, C. H. (2002). Canais de distribuicao: elementos para uma metodologia de planejamento de canal complementar (Dissertação (Mestrado em Administração)). Universidade Paulista, São Paulo.

Zeithaml, V. A. (1988). Consumer Perceptions of Price, Quality, and Value: A Means-End Model and Synthesis of Evidence. The Journal of Marketing, 52(3), pp. 2-22. http://dx.doi.org/10.2307/1251446

Zeithaml, V. A., Parasuraman, A., \& Berry, L. L. (1990). Delivering quality service: balancing customer perceptions and expectations. New York: Free Press.

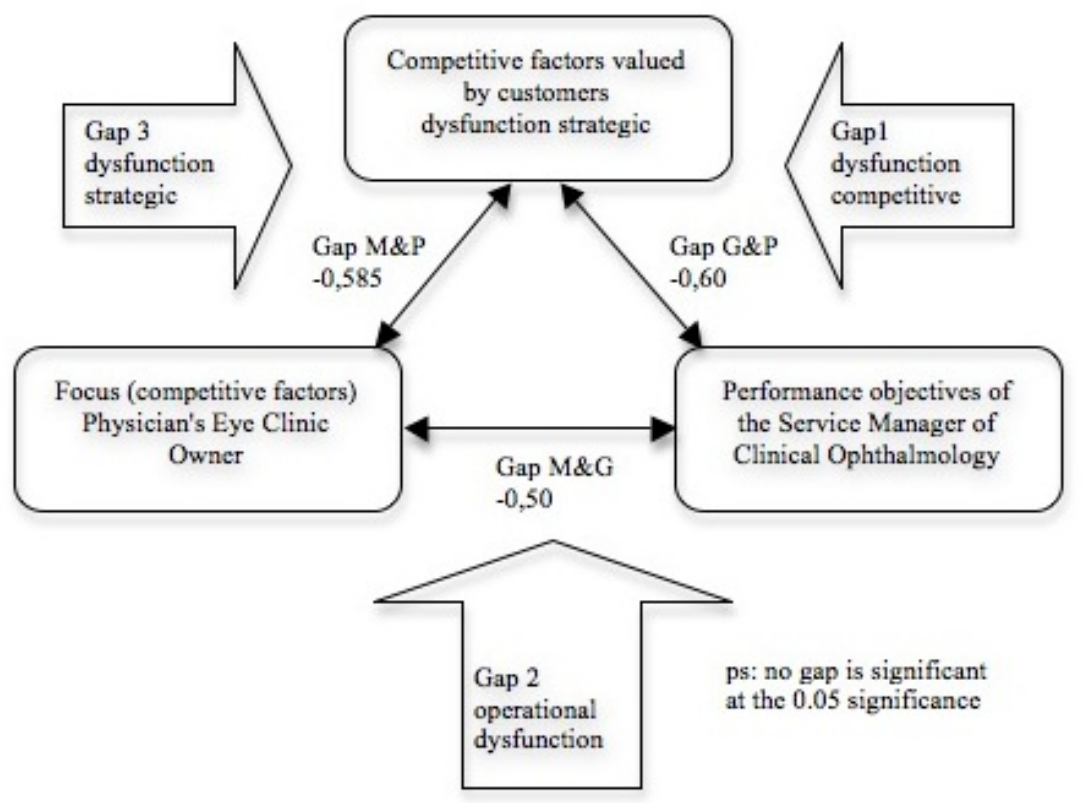

Figure 1. Gaps observed for all the ophthalmology clinics surveyed. The values are expressed as median. Note that the gap between doctor and patient owner (gM\&P) is slightly smaller than the gap between the manager and the patients (gG\&P). 